\title{
Origens e prospectiva do pensamento político-pedagógico de Paulo Freire
}

Afonso Celso Scocuglia

Universidade Federal da Paraíba

\section{Resumo}

0 artigo tem por objetivo examinar as relações entre educação e política ao longo da construção do discurso de Paulo Freire. Nesta perspectiva, são trabalhadas as ligações das propostas do autor com o nacional-desenvolvimentismo e o com o populismo nos anos de 1950 e 1960, indicando-se as principais influências teóricas que constroem o pensamento do "primeiro" Paulo Freire, especialmente as correntes existencialistas e personalistas que alicerçam seu pensamento cristão progressista e as influências de intelectuais do ISEB.

A seguir, busca-se identificar a progressão teórica do autor, a começar das influências modificadoras de correntes marxistas. Um outro conjunto de influências teóricas - Marx, Hobsbawn, Goldman, Lukács, Gramsci, Sartre -, somadas a críticas e autocríticas, permitem identificar a instituição de um "outro" Paulo Freire, momento em que o discurso freireano é inundado pela preocupação com a "politicidade da educação" e com a "educabilidade da política”. Neste sentido, discute-se a questão da inseparabilidade educação-política e suas especificidades.

Finalmente, investe-se nas possíveis sínteses do pensamento do autor, esboçando um itinerário das origens e da prospectiva político-pedagógica de Paulo Freire. Inerente à construção deste artigo, está a convicção de estarmos tratando de uma das contribuições pedagógicas mais importantes do século XX e, como tal, de uma proposta educacional necessária ao nosso futuro como sociedade autônoma, esperançosa e dialógica, embora permanentemente indignada com as injustiças sociais e os direitos humanos negados ou violados.

\section{Palavras-chave}

Pensamento freireano - Diálogo - Conscientização - Político-pedagógico. 


\section{Origins and prospect of Paulo Freire's pedagogical-political thinking}

Afonso Celso Scocuglia

Universidade Federal da Paraíba

Correspondence:

Rua Juvenal Mário da Silva, 463 58038-510 - João Pessoa, PB. e-mail:

scocuglia@zaitek.com.br

\section{Abstract}

This paper intends to examine the relationship between education and politics along the construction of the Paulo Freire's discourse. With this respect, the paper deals with the relationship between Freire's proposals and the "developmental nationalism" movement, and with the populism of the 50's and 60 's. The main theoretical influences on this first phase of Paulo Freire's are pointed out, in particular the existentialist and personalist veins upon which his progressive Christian thinking is based, and the influences of the intellectuals from the ISEB.

The paper then seeks to identify Freire's further theoretical development, beginning with the modifying influences of the Marxism. Other theoretical influences - Marx, Hobsbawn, Goldman, Lukács, Gramsci and Sartre - combine with Freire's critical and self-critical thinking to produce a "new" Freire, a time in which his discourse is engaged in the concern with the "politicity of education" and with the 'educability of politics'. In this sense, the issue of the inseparability of education and politics and their specifics is discussed.

Finally, some of the possible syntheses of Freire's thinking are examined, and an itinerary of his origins and of his pedagogical-political perspective is outlined. Intrinsic to the making of this paper is the belief that it deals with one of the most important pedagogical contributions of the twentieth century that, as such, constitutes an educational proposal that is necessary to our future as an autonomous society, hopeful and dialogic, although permanently outraged at the violation of human rights and at social injustice.

\section{Key words}

Freire's thinking - Dialogue - Consciousness Political-pedagogical. 
0 esforço principal deste trabalho incide sobre a compreensão das origens e da prospectiva do pensamento político-pedagógico de Paulo Freire - especialmente sobre o dimensionamento político de sua práxis educativa/pedagógica - mediante a captação de seus núcleos temáticos básicos.

Especificamente, tivemos como preocupação o entendimento: (a) das relações entre a educação e a política nos momentos iniciais do discurso freireano; (b) das relações entre a educação e a política ao longo do desenvolvimento/mudança do pensamento do autor; (c) da importância que estas relações adquirem, constituindo o fio condutor da progressão de seu discurso; (d) das substanciais diferenças no tratamento analítico destas relações e das notórias mudanças qualitativas das mesmas, a exemplo da conceituação relativa à "conscientização", ao “diálogo" e à "ação cultural”.

A realização do estudo partiu de duas questões preliminares: Por que estudar as relações educação-política em Paulo Freire ? Por que estudar estas relações ao longo da progressão do seu discurso principal, iniciando com seus primeiros escritos, percorrendo seu itinerário intelectual de relevo, até sua produção mais recente?

Podemos, de início, responder que da década de 1960 à primeira metade da de oitenta, parte significativa dos trabalhos publicados sobre a obra de Paulo Freire tem como base de referência teórica exclusiva proposições colocadas nas suas reflexões iniciais', oriundas das primeiras experiências com a alfabetização de adultos no Brasil, entre 1961 e abril de 1964, girando em torno do que se conhece como "Método Paulo Freire". Certamente, em termos de reflexão teórica, essa não é a parte mais substanciosa e crítica da sua vasta obra. Estas restrições das análises nos limites iniciais da obra prático-teórica de Freire e a tomada de suas primeiras propostas como definitivas e irreversíveis implicam em equívocos grosseiros e tendem a perpetuar a falsa idéia de uma obra limitada e anacrônica. Concordamos com Rossi (1982), quando diz que

(...) um erro comum na análise do trabalho de Freire é exatamente ignorar-se a clara evolução das suas concepções, que começa por um idealismo moldado por sua vinculação ao pensamento católico moderno, chegando até seu crescimento em direção à abordagem dialética da realidade, que caracteriza seus últimos escritos. Se sua Educação como prática da liberdade é influenciada por concepções de Jaspers e Marcel no nível filosófico, a Pedagogia do oprimido já mostra uma clara aproximação da melhor tradição radical, de Marx e Engels aos modernos revolucionários (...) e de outras linhas de análise crítica contemporânea (...). (p.90-91)

Com efeito, o corte realizado na obra freireana e a consideração das propostas iniciais como fixas têm, como conseqüência, o desconhecimento da indiscutível progressão do seu pensamento nos anos setenta e oitenta e a ignorância da sua práxis histórica. Os momentos preliminares da imensa trajetória prático-teórica de Freire devem ser compreendidos enquanto parte de um longo itinerário, no qual o autor conseguiu superar equívocos, ambigüidades e idealismos, submetendo-se à crítica e, especialmente, à autocrítica ${ }^{2}$.

1. A maioria dos trabalhos sobre Paulo Freire, publicados até o final dos anos oitenta no Brasil, leva em consideração apenas seus escritos iniciais. A desconsideração da continuidade de sua obra, na qual vários conceitos, categorias e relações são revistos sob outras óticas, constitui obstáculo intransponível à compreensão do pensamento político-pedagógico do autor, como um todo.

2. Uma das principais virtudes de Paulo Freire era a de submeter-se a críticas, em debates e reuniões, encarando-as seriamente, a ponto de modificar conceitos a partir delas. Neste caminho, a autocrítica permanente faz parte de seu itinerário intelectual, implicando uma certa seqüência de seus escritos, o que permite rever e alterar categorias e relações. 0 tratamento dado à "conscientização" evidencia tal atenção às críticas sérias. Aliás, o expediente de criticar Paulo Freire já rendeu muitas teses, livros, além de projeções indevidas a seus autores. 
Estamos convencidos de que o substancial avanço das suas posições político-pedagógicas faz com que suas idéias e sua prática sejam referências marcantes no campo da educação contemporânea.

Devemos destacar, com especial atenção que, assim como ocorre com várias categorias, o relacionamento educação-política sofre substanciais mudanças analíticas no transcorrer do discurso deste educador. Freire declara que, inicialmente, "não enxergava" este relacionamento e a posteriori descobriu "aspectos políticos” na educação. A partir da produção dos anos setenta, seu discurso registra a inseparabilidade educação-política, bem como sua preocupação em entender suas respectivas especificidades. Em suma, podemos perceber a existência de "vários" Paulo Freire ${ }^{3}$.

Por isso, enquanto um pensamento não-definitivo - que se sabe incompleto por sua própria rigorosidade e que se quer aberto, não-dogmático e não-determinista - a obra de Paulo Freire encontra-se permanentemente sequiosa de novas descobertas e novas experimentações.

Entendemos que se suas propostas político-pedagógicas não permitissem novas descobertas e novas experimentações, como partes intrinsecas da sua própria concretude e de sua disseminação, tornar-se-iam inertes e enrijecidas. Suas propostas foram feitas para serem recriadas, conforme o cotidiano, o imaginário, os interesses e os valores, conforme as condições de vida de seus praticantes, sejam educandos ou sejam educadores.

\section{O itinerário da pesquisa realizada}

Torna-se necessário um esforço de aplicação dos caminhos histórico e dialético para a análise do percurso intelectual de Freire no campo temático das relações educaçãopolítica.

Histórico, no sentido de pesquisarmos o pensamento do autor sob o prisma do tempo relativo à sua produção discursiva, buscando contextualizar sua prática e sua teoria em cada um dos vários momentos componentes de sua trajetória. Destarte, Freire exige dos estudiosos da sua obra a apreensão das suas propostas político-educativas com tempo e espaço determinados (no Brasil, no Chile, nos Estados Unidos, na Europa, na África; antes, durante exílio e após a volta para "reaprender" o Brasil, com a Anistia aos presos e exilados políticos do Estado militar, em 1979). Só assim esses estudiosos conseguem dimensionar, com clareza, a construção do seu pensamento.

Para efeito de pesquisa, dividimos nossa investigação nos três momentos históricos do discurso freireano: o primeiro, correspondente aos escritos realizados entre 1959 e 1970; o segundo, correspondente à década de setenta; e o terceiro com seus escritos mais recentes nos anos oitenta e noventa. Podemos, didaticamente, falar em "primeiro, segundo e terceiro" Paulo Freire. Esta leitura "cronológica" (mas, não linear) é facilitada pelo próprio autor que faz com que a seqüência dos seus escritos siga (sem rigidez proposital) uma certa ordem organizativa, de modo que o texto seguinte retome discussões e propostas colocadas anteriormente. 0 leitor atento verifica uma certa intencionalidade num pensamento com introdução-desenvolvimento-conclusão, sem constatar idéias fixas ou conceitos irreversíveis. Devemos ressaltar, com efeito, que os três momentos acima mencionados não foram tratados dicotomizadamente, mas enquanto componentes de um corpus: o da construção do seu pensamento político- pedagógico.

3. Uma das capacidades de Paulo Freire era a sua constante progressão. Como homem do seu tempo, "cada vez mais incerto de suas certezas", advogado do processo de conhecimento crítico, consciente de sua incompletude, Freire não parou de "fazer história" e "ser feito por ela". 0 Freire de Educação como prática da liberdade $\left(1965,1^{\text {a }}\right.$ edição) não é o mesmo de Política e educação (1993). 
Dialético, na busca da compreensão das "totalidades" e das "contradições" internas do discurso freireano. Um discurso que ao falar da pedagogia do oprimido denuncia a opressão; ao denunciar a educação "bancária" propõe a educação "problematizadora”; ao colocar as dificuldades dos subalternos em se organizarem como classe, mostra as facilidades dos opressores em "ser classe" no próprio exercício da direção/dominação. Um discurso que, ao falar da necessidade da ação dialógica como matriz da pedagogia do oprimido, não se esquece do autoritarismo e da precariedade de grande parte das nossas escolas que, ao excluírem milhares de crianças todos os anos, tornam-se fábricas de analfabetos jovens e adultos. São muitos os exemplos da presença permanente da dialeticidade nos escritos de Paulo Freire. Esforçamo-nos na compreensão dessa dialética para apreendermos a construção histórica das idéias do autor, especificamente quanto às conexões educação-política ${ }^{4}$.

\section{Principais escritos de Paulo Freire: panorama temático}

Colocadas as justificativas das abordagens escolhidas, buscaremos informar o leitor sobre a operacionalização deste trabalho, cujo ponto de partida incidiu sobre o levantamento da obra do autor publicada no Brasil. É importante salientar que grande parte do que foi publicado por Freire fora do país já está traduzido e/ou reeditado e, também, registrar a extensa lista de publicações simultâneas realizadas no Brasil e no exterior. Todas estas referências encontram-se indicadas nas notas de rodapé e nas referências bibliográficas.

Em relação aos principais livros selecionados para a análise discursiva de conteúdo temático, ${ }^{5}$ devemos começar destacando Educação como prática da liberdade (1984a) e Pedagogia do oprimido (1984b). Esses escritos marcam o início da vasta bibliografia de Freire, trazendo suas preocupações e propostas metodológicas para a alfabetização de adultos e tentando formular as primeiras matrizes de uma "pedagogia da resistência" aos processos de opressão desenvolvidos em larga escala por toda a América Latina nos anos sessenta, para não dizer há séculos.

No livro Ação cultural para a liberdade e outros escritos (1976), a preocupação com a politicidade das práticas educativas com adultos, como processos de conhecimento não-neutros, transparece nitidamente. Também é fundamental para o nosso conteúdo temático a entrevista com os integrantes do Instituto de Ação Cultural (IDAC) ${ }^{6}$ na qual Freire mostra sua compreensão de uma educação mergulhada no conflito entre classes sociais (embora sua análise nunca tenha se restringido a tal enfoque) clarificando suas aproximações teóricas com diversos autores marxistas identificadas a partir dos últimos capítulos da Pedagogia do oprimido, começando do próprio Marx e, depois, na seqüência dos seus escritos, chegando a Gramsci.

4. Temas como "a educação como processo de elevação cultural das massas populares", o educador como "novo intelectual" (especialista e organizador), o partido educador, entre outros, aproxima o discurso de Freire de certos "recortes" político-educativos gramscianos. Estas aproximações serão notadas na seqüência do texto.

5. Os subtemas através dos quais abordamos as relações educação versus política no discurso de Paulo Freire foram codificados em função da presença (constante ou esporádica) que assumem no seu discurso e pela importância de cada um dos subtemas. Assim, no "primeiro" Freire não podia estar ausente educação- conscientização, educação-liberdade, educação-nacionalista/populista, educação desenvolvimentista. Depois, não poderia faltar pedagogia do opressor versus pedagogia do oprimido. 0 mesmo se pode dizer na seqüência do pensamento do autor.

6. Depois de passar pela Bolívia e pelo Chile (1964-69) e alguns meses nos EUA (onde escreve o livro Ação cultural para a liberdade e outros escritos, reunião de vários textos importantes que discutem os conceitos e categorias dos livros anteriores, corroborando-os ou modificando-os), Paulo Freire vai dirigir o Departamento de Educação do Conselho Mundial das Igrejas, em Genebra, onde atua por toda a década de 1970. Com alguns exilados funda e trabalha no IDAC - Instituto de Ação Cultural - como co-responsável por trabalhos na África (Guiné-Bissau etc) e por várias publicações. 
$\mathrm{Na}$ seqüência da produção freireana, principal atenção e destaque merecem as incorporações teóricas definidoras da "infra-estrutura” econômica. Até então, Freire tecia sua análise quase exclusivamente calcado nas esferas da chamada "superestrutura". Estas incorporações são especialmente importantes para a progressão teórica do autor e se revelam nos "escritos africanos" veiculados nas Cartas a Guiné-Bissau (1980), em A importância do ato de ler (1982a), em Quatro cartas.... na coletânea A questão política da educação popular (Brandão, 1980) e em outros escritos como, por exemplo, em Vivendo e aprendendo (1980c). Nestes escritos torna-se notória a proximidade teórica com teses gramscianas ${ }^{7}$ incorporadas, também, através das leituras da obra de Amílcar Cabral (1976), líder da luta anticolonial guineense.

Quanto aos escritos mais recentes, cuja parcela mais significativa encontramos nos livros dialógicos realizados com outros intelectuais, destacamos: Sobre educação (1982b e 1984d) e Aprendendo com a própria história (1987b), com Sérgio Guimarães; Pedagogia: diálogo e conflito (1985a), com Sérgio Guimarães e Moacir Gadotti; Por uma pedagogia da pergunta (1985b), com Antonio Faúndez; Essa escola chamada vida (1986b), com Frei Betto; Medo e ousadia - o cotidiano do professor (1987a), com Ira Shor, e Na escola que fazemos... (1988), com Adriano Nogueira.

Também podemos destacar, entre os últimos trabalhos veiculados, A Educação na cidade (1991), livro que contém reflexões sobre os desafios na Secretaria Municipal da Educação de São Paulo, na gestão da prefeita Luíza Erundina (1989-92). Destacamos, ainda, Pedagogia da esperança (1992) e Politica e educação (1993). Neste último, o autor se posiciona face às incertezas e às decepções provenientes da "crise de paradigmas" nas ciências sociais e na educação, investindo firmemente contra os “determinismos" teleológicos da história (encampados, por exemplo, nos positivismos e parte significativa dos marxismos).
São importantes, ainda, as entrevistas e os artigos publicados nas revistas Educação e Sociedade $N .^{\circ} 1$, 3 e 10 (1978/79/80); em Paulo Freire ao vivo (1983b); na revista Ensaio N. ${ }^{\circ} 14$ (1985c). Devemos enfatizar, também, o debate realizado no Curso de Mestrado em Educação na UFPB (1986a), onde a temática educação-política foi uma das prioridades. Debate gravado e datilografado no qual, por vários dias, tivemos a oportunidade de conhecer "de perto" o vigor e a rigorosidade de Paulo Freire.

Em suma, foi compilado e analisado vasto material cuja análise esteve centrada nas múltiplas relações político-educativas do discurso de Freire.

\section{O “primeiro” Paulo Freire}

Para tentarmos uma síntese do "primeiro" Freire, levamos em consideração três dos seus escritos mais representativos: Educação e atualidade brasileira, Educação como prática da liberdade e Conscientização. Notamos, mesmo no interior deste "primeiro" momento, as mudanças dos conceitos e da rede de relações que envolvem o binômio educação-política. Destaca-se a visão da sociedade brasileira "em trânsito" para a modernização e um posicionamento implícito na disputa pelo poder político entre as forças agro-comercial e urbano-industrial (em favor da segunda), frações hegemônicas das classes dirigentes da segunda metade da década de 1950 e da primeira metade de sessenta. A problemática da difusão de uma

7. Nos "escritos africanos" a influência de Antonio Gramsci, também influenciador do líder da guerrilha guineense Amílcar Cabral, pode ser notada com freqüência. De Cabral, Freire usa o "suicídio de classe". Tal conceito indica a passagem dos intelectuais integrantes das classes médias (ou, segundo o autor, da "pequena burguesia") para o pólo dos subalternos, ao se identificarem com seus interesses, necessidades e valores emancipatórios. Gadotti chama os educadores que efetuam essa passagem de "trânsfugas de classe" (1985a). 
"ideologia da consciência nacional" ganha destaque quando Freire diz que "é preciso aumentar o grau de consciência (do povo) dos problemas de seu tempo e de seu espaço. É (preciso) dar-lhe uma ideologia do desenvolvimento" (1982, p.28).

Importante perceber que educar as massas populares, segundo ele, significava "conquistá-las para o processo de desenvolvimento nacional" e para a "participação crítica" no mesmo. Os interesses nacionais correspondiam aos interesses de frações dominantes, embora, ambiguamente, percebamos interesses populares também embutidos nas perspectivas nacionalistas. 0 populismo arvorava-se a capacidade de intermediar tanto os interesses convergentes como os interesses opostos.

Assim, conquistar a "consciência crítica" implicava alcançar um nível de consciência que contribuisse para a hegemonia de uma "moderna" classe dominante e de um projeto de reformas (agrária, educacional, de saúde, de industrialização auto-sustentada etc) de base. A conquista da criticidade, para Paulo Freire, não passava (ainda) pela questão dos conflitos entre as classes sociais e, assim, não significava a busca da "consciência de classe" para os subalternos. Não se tratava (como o autor advogará, posteriormente, pela via lukcasiana) de engendrar a "consciência da situação histórica das classes trabalhadoras". A conscientização, como intermediação político-pedagógica, poderia atingir todas as classes e o diálogo deveria conduzir o "entendimento geral para o desenvolvimento de todos", da Nação, que estaria "acima" de todos os interesses particulares, inclusive dos interesses classistas. A alfabetização de adultos, disseminada em larga escala (havia um projeto de instalação de 20.000 "círculos de cultura" em todo o país em 1964), poderia contribuir, com eficácia e rapidez, para a consecução hegemônica em curso, conscientizando e tornando milhares de indivíduos aptos a votarem em candidatos considerados "progressistas".
No entanto, encontramos em Educação como prática da liberdade um conjunto de reflexões que mostram certa evolução em relação aos posicionamentos anteriores citados. Embora presente, a forte influência do 1SEB (Instituto Superior de Estudos Brasileiros) tende a diminuir e os alicerces teóricos marcados por um certo emaranhado de idéias buscam uma maior clarificação coadjuvados pela possibilidade de, no exílio chileno (1964-69), tomar certa distância dos acontecimentos brasileiros abortados pelo golpe de 1964. Logicamente, inclusive pelo curto lapso de tempo, as mudanças dos posicionamentos prático-teóricos não significavam alterações radicais. A não inclusão da análise econômica da sociedade impedia a nitidez no processo de desvelamento da realidade e o próprio autor, com capacidade de absorver críticas e de autocriticar-se, reconhece tais equívocos.

No "ziguezague" do raciocínio freireano, a educação instrumentalizaria o "povo emergente mas desorganizado, ingênuo e despreparado", marcado por índices alarmantes de analfabetismo, para a construção de uma outra Nação, moderna e mais justa, democrática e liberal. Havia uma crença explícita no papel das "instâncias superestruturais" na tentativa organizada dessas conquistas "para todos".

Parece-nos fundamental destacar que o "pano de fundo" da arena da mudança social estava excessivamente consagrado às transformações internas dos seres humanos ou, em outras palavras, através das transformações das "consciência individual" (herdeira do idealismo iluminista), nas quais a educação e, especialmente no caso de Freire, a alfabetização da imensa legião de adultos, tinha posição de vanguarda.

De outro ângulo, é oportuno notarmos, como o faz Weffort no prefácio de $E d u$ cação como prática da liberdade (1984a), que: 
Uma pedagogia da liberdade pode ajudar uma política popular, pois a conscientização significa abertura à compreensão das estruturas sociais como modos de dominação e violência (...). A experiência brasileira nos sugere algumas lições curiosas, às vezes até surpreendentes em política e educação popular. Foi-nos possível esboçar, através do trabalho de Freire, as bases de uma verdadeira pedagogia democrática. Foi-nos possível, além disso, começarmos, com o movimento de educação popular, uma prática educativa voltada de modo autêntico, para a libertação das classes populares. (p.15;25)

Não obstante, precisamos indagar: as propostas político-pedagógicas de Paulo Freire, nesse primeiro momento de sua práxis, serviram como instrumento populista de manipulação dos setores que dirigiam o Estado brasileiro, representados diferentemente por Goulart, Arraes, Brizola etc, como defende Vanilda Paiva (1980) ou serviram como instrumento das forças médias e populares na direção de uma sociedade mais democrática, menos injusta, mais solidária?

No nosso entendimento, a práxis político-pedagógica freireana serviu muito mais à mobilização, à organização, à difícil conquista da representatividade e da cidadania das camadas populares do que à manipulação típica dos populismos. 0 verdadeiro pânico causado em boa parte das elites diante da multiplicação dos grupos que levavam suas propostas alfabetizadoras em frente demonstrava a positividade de uma ação pedagógica politicamente solidária aos interesses populares - tidos como desestabilizadores da "ordem" e do "progresso" (da minoria). Por outro lado, demonstrava que naquilo que era considerado "perigoso e subversivo" pela minoria, residia aquilo que era positivo e progressista para a maioria dos subcidadãos de "segunda e terceira classes". Se a proposta pedagógica de Freire continha equívocos e sua postura política convivia com o populismo, defendendo o nacional-desenvolvimentismo, o concreto é que sua prisão e o seu exílio forçado por mais de quinze anos evidenciaram um indiscutível poder político ancorado numa prática educativa ligada às raízes e aos conhecimentos populares.

Não obstante, apesar de saber da positividade e do progresso qualitativo gerado por suas propostas no campo da alfabetização e da educação em geral, Freire autocritica-se:

(...) Em meus primeiros trabalhos, não fiz quase nenhuma referência ao caráter político da educação. Mais ainda, não me referi, tampouco, ao problema das classes sociais, nem à luta de classes (...). Esta dívida refere-se ao fato de não ter dito essas coisas e reconhecer, também, que só não o fiz porque estava ideologizado, era ingênuo como um pequeno- burguês intelectual. (1979, p.43)

Ora, quem tem a capacidade de autocriticar-se da maneira exposta acima, demonstra capacidade de progredir, de buscar novos caminhos e de aprofundar suas posições, incorporando novos parâmetros práticos e teóricos. E, neste sentido, alçar vôos mais profícuos na direção da construção de um pensamento-ação cada vez mais imbricado com os interesses ético-solidário-emancipatórios (contra-hegemônicos) das múltiplas camadas populares, a começar de sua sobrevivência/trabalho e da conquista da cidadania negada, inclusive, pela via educacional.

\section{A progressão do pensamento político-pedagógico de Paulo Freire}

Tentar apreender a progressão de um pensamento dialético, que busca a compreensão da "totalidade interna" assim como suas "contradições", realizar isto de modo associado a uma constante reconstrução analítica constitui tarefa das mais difíceis. 
Concordamos com os editores de Diálogo com Paulo Freire (1979) quando, apresentando-o, destacam que o seu pensamento

possui um itinerário definido: parte da análise de programas de educação de adultos e de uma crítica radical aos mesmos, para chegar, depois, a uma solução que denomina 'ação cultural libertadora', a qual se projeta como um verdadeiro programa de ação nos setores marginalizados, oprimidos e dominados. (p.1)

A nosso ver, trata-se de um pensamento marcado por dois grandes "pólos de irradiação" inseparáveis: um, predominantemente psicopedagógico (cuja parte mais elaborada aparece na Pedagogia do oprimido) e outro, radicalmente político-pedagógico (construído basicamente a partir das reflexões de Ação cultural para a liberdade e outros escritos). Nos múltiplos caminhos nuclearizados por esses dois pólos, os amálgamas teóricos se reconstroem com autocríticas das "ingenuidades” e com a percepção de aspectos idealistas. A mais notória das reconstruções ocorre a partir das aproximações às idéias "marx-gramscianas", predominantemente "culturais", com o rechaço do economicismo (da vulgata) marxista. Como observa Carlos Torres (1979),

É por isto que quem pretender seguir o itinerário intelectual de Freire se defrontará com um conjunto de caminhos diversos, amalgamados numa estranha conexão. Deverá transitar por textos filosóficos, mais especificamente gnoseológicos ou, às vezes, epistemológicos. Deverá aprofundar-se em considerações teológicas...deverá indagar-se sobre sociologia do conhecimento...deverá considerar as implicações psicossociais do seu método. Deverá opinar sobre o projeto educativo-pedagógico que Freire postula sob o nome de ação cultural libertadora. Deverá, principalmente, em seus últimos escritos seguir o fio condutor de suas reflexões sobre a união dialética da liderança com as massas, os projetos de organização política do oprimido, vistos à luz da ciência política. (p.6)

Acrescentaria, ainda, na seqüência de sua produção (anos oitenta) a prioridade dada aos movimentos sociais como contextos político-educativos, associado à analise do Partido (PT) como educador-educando ("intelectual coletivo") popular e, mais recentemente, o (re)alicerce teórico de um pedagogo "pós-moderno progressista" em Política e educação (1993).

Nesse último livro, a ênfase analítica centrada na "luta de classes" cede espaço para as lutas que marcam o cotidiano, as novas mentalidades, a sobrevivência teimosa dos milhões seres "subumanos" que foram marcados pelo cinismo capitalista-liberal e pelos horrores dos totalitarismos, reprovando as estreitezas da razão positivista em sua versão liberal atualizada, e advogando a importância renovada da educação, inerente ao novo papel da "subjetividade na História" dos indivíduos e dos grupos sociais.

Com efeito, a "descoberta" da politicidade da educação, a partir dos "aspectos políticos” presentes na Pedagogia do oprimido, depois advogando a reciprocidade dos atos educativos com os atos políticos, foi articulada em nível teórico, pela incorporação aberta de preceitos marxistas (em "estranhas conexões”, como disse Torres) e por uma aproximação a alguns temas gramscianos. Não afirmamos que Marx-Engels e Gramsci, mais Sartre, Lukács, Amílcar Cabral, entre outros, determinaram a ruptura com posições liberalizantes, nacionalistas e desenvolvimentistas e, certamente, populistas, dos anos 50 e 60 . Como coloca o próprio autor, ele não foi trabalhar com os grupos populares "por causa de Marx”, ao contrário, foi procurar auxílio nos marxismos (não-ortodoxos) para compreender esses grupos.

Façamos, então, uma síntese retrospectiva destas incorporações e de suas reelaborações 
ao longo do itinerário freireano.

Primeiramente, percebeu-se uma incorporação aberta de certos parâmetros políticos e ideológicos propostos pelos clássicos socialistas, especialmente Marx - destacando-se várias referências a escritos como $A$ sagrada familia, A ideologia alemã e Teses sobre Feuerbach, relativos à denominada "superestrutura". $\mathrm{Na}$ Pedagogia do oprimido já aparecem "classes" no contexto da opressão social, embora não constituam, ainda, categorias centrais da construção do seu discurso. Em Ação cultural para a liberdade e outros escritos a educação começa a ser efetivamente pensada no interior do conflito de classes, como ato de conhecimento "de classe" em busca da mobilização/organização dos oprimidos, enquanto "ação cultural" que constrói a "consciência de classe" - e, esta só seria conquistada no conflito, na luta pela mudança estrutural da sociedade. Aqui, Goldman, Lukács e Hobsbawn contribuem de modo fundamental.

No entanto, as incorporações dos vários "marxismos", nos quais predominam preocupações analíticas "superestruturais", também cedem espaços para a aproximação teórica "infra-estrutural" (econômica, sem ser economicista), visíveis nos "escritos africanos", como em Cartas à Guiné-Bissau e nos vários livros dialógicos Pedagogia: diálogo e conflito, Por uma pedagogia da pergunta, Medo e ousadia o cotidiano do professor, Essa escola chamada vida, escritos dos anos setenta e oitenta. A categoria mais notória a passar por novo tratamento analítico é "trabalho". 0 que antes era pensado via "dialética senhor-escravo" de Hegel, subsidia-se em $O$ capital (Marx), na admiração por Amílcar Cabral e aparece como "contexto político-educativo" no qual a "produção" é entendida enquanto balizadora dos "conteúdos programáticos" escolares e da própria alfabetização dos adultos. Interessante notar a apropriação de alguns conceitos gramscianos, como os "novos intelectuais" e o "partido como intelectual-coletivo".
A inclusão da categorização "infra-estrutural" como base relacional do que ocorre na "superestrutura" da sociedade, ou seja, a priorização do trabalho e da produção coletiva como "locus" político-educativo, marcam um novo ponto no constante "recomeço" do discurso de Paulo Freire. A defesa de uma análise necessariamente "interestrutural" (onde a "superestrutura" não seja, nunca, mero reflexo das relações econômicas), ao mesmo tempo em que não eclipsa questões existencialistas e personalistas - amalgamadas por uma "teologia da libertação" - evidencia a atualização permanente de suas preocupações político-educativas, associadas a um ferrenho antidogmatismo.

Não podemos deixar de lembrar que um dos alicerces indeléveis da prática e da teoria de Paulo Freire é a questão da democracia: liberal, social, socialista... mas, sempre, democracia. Se há uma questão central que percorre o discurso freireano, em todos os seus diversos e diferentes momentos, esta é a questão da educação e da pedagogia enquanto prática e teoria contribuintes da "radicalidade democrática", mesmo quando se evidenciaram equívocos do populismo "de esquerda” e do nacionalismo-desenvolvimentista dos anos 1950 e 1960. Importante enfatizar que, mesmo aproximando-se dos marxismos e de modelos que encamparam posições autoritárias, Paulo Freire nunca admitiu o autoritarismo, a ditadura, nem "por motivos justificáveis" como advogam certos setores de "esquerda".

Se nos seus escritos a "humanização não se fará sem a destruição da sociedade de exploração e da dominação humana”, o itinerário da consecução de tal possibilidade é sempre democrático. 0 que, entre outras coisas, o torna sempre atual e incluso, por exemplo, nas discussões da "crise dos paradigmas", no final do século XX, onde a busca de "outras razões" pode recolocar a ação humana no centro das decisões do mundo. Decisões 
fundadas na ética, na solidariedade social e na conquista intransigente da radicalidade democrática.

\section{Considerações finais}

Nesta seqüência de sínteses, o que poderíamos enfatizar como principal em termos das “categorias próprias" do pensamento político-pedagógico do nosso autor? Em outras palavras, o quê (e como) os vários amálgamas teóricos mudaram (ou não) categorias como "diálogo", "conscientização", "pedagogia do oprimido" etc?

Uma constatação é fundamental: "separando" o pensamento político do pedagógico (para tentar ser didático na explicação), notamos que a "ruptura" política em direção adesiva aos trabalhadores (como classe sócio-política) é acompanhada por uma "evolução" pedagógica. Esclarecendo: a educação e a pedagogia não deixaram de realizar-se via diálogo, não deixaram de priorizar o ato de conhecimento, a busca da consciência crítica. Mas, o que antes era predominantemente psico-pedagógico, passou a ser prioritariamente político-pedagógico, sem anular as preocupações psicossociais que embasam suas propostas desde seus primeiros escritos, de base escolanovista (principalmente relativa às idéias de Dewey e de Anísio Teixeira).

0 momento que marca essa passagem, traz o "oprimido" como categoria central discursiva e a denúncia da "desumanização opressora" como caminho político de emancipação. A consciência da opressão e o conseqüente combate à ideologia do opressor "hospedada na ingenuidade da consciência oprimida", dão a tônica da mudança do enfoque analítico. Pensamos que o último capítulo da Pedagogia do oprimido, localiza o segmento de ruptura do discurso freireano e a emersão de um "outro Paulo Freire" - diferente de Educação como prática da liberdade, por exemplo - que se consubstancia em Ação cultural para a liberdade e outros escritos, nas Cartas à Guiné-Bissau e em toda seqüência dos seus escritos mais recentes.

0 "diálogo", admitido de início como possibilidade de mediação "interclasses" é rechaçado como tal e entendido como "ação entre os iguais e os diferentes, mas contra os antagônicos" nos conflitos sociais.

A “conscientização” engendrada com a contribuição de Vieira Pinto e dos isebianos em "estágios crescentes de consciência" (ingênua, transitiva, crítica) desloca-se, gradativamente, para "consciência de classe" lukacsiana.

Com efeito, a adoção das "classesna-luta-de-classes”, antes ausente ou colocada de forma "nebulosa", constitui importante deslocamento da sua análise social, às vezes de forma até repetitiva (talvez em função das críticas aos seus escritos primeiros, nos quais a proximidade com o nacionalismo-desenvolvimentista-populista eclipsavam tais conflitos) e, por outras vezes, exagerada. Importante: Freire não admite em seus escritos a "luta de classes como motor da História”, que (inexoravelmente) desembocaria no socialismo e no comunismo, como o faz Marx.

Nesse sentido, com a política sendo "substantiva" e a pedagogia "adjetiva”, a concepção inicial de uma educação para a mudança "interna" do homem, via conscientização de âmbito psico-pedagógica e que implicaria a transformação de toda a sociedade, é "virada de ponta cabeça" (como Marx tentou com Hegel, nem por isso deixando de ser, parcialmente, hegeliano).

Com efeito, nos seus últimos escritos, Freire concentrou-se na "criação histórica" com os trabalhadores, estudantes, professores etc, em seus sindicatos, associações, comunidades, escolas...- de uma outra educação que só seria possível na mudança profunda da sociedade, da política(gem), da ética, do cotidiano dos indivíduos e dos grupos sociais. Uma educação de resistência, que não aceita a 
exploração continuada dos oprimidos ou outros pretextos escusos. Uma educação "para a autonomia e para a capacidade de dirigir" ou, como defendia Gramsci, para a "contrahegemonia dos subalternos”. Uma educação para formar cidadãos plenos e, não, uma educação que além dos milhares de alunos sumariamente expulsos (ou sem acesso efetivo) da escola, continua a formar subcidadãos de segunda, terceira, quarta... classes. Uma "educação cidadã", que combate o cinismo liberal globalizado co-responsável pela miséria e pela catástrofe social dos nossos dias. Uma educação que "não sendo fazedora de tudo é um fator fundamental na reinvenção do mundo". E, que
(...) como processo de conhecimento, formação política, manifestação ética, procura da boniteza... é prática indispensável dos seres humanos (dos homens e das mulheres) e deles específica na História como movimento, como luta. A História como possibilidade não prescinde da controvérsia, dos conflitos que, em si mesmos, já engendrariam a necessidade da educação (Freire, 1993, p.14).

Nessa história a ser construída, Paulo Freire reivindicava seu papel de "intelectual-ficando-novo", de educador-educando popular e de contribuinte ativo da mudança social - ontem, com sua produção educativa/pedagógica, hoje e amanhã com a riqueza de seu legado.

\section{Referências bibliográficas}

BRANDÃo, Carlos (Org.) A questão política da educação popular. São Paulo: Brasiliense, 1980.

FREIRE, Paulo. A importância do ato de ler. São Paulo: Cortez, 1982a.

Ação cultural para a liberdade e outros escritos. Rio de Janeiro: Paz e Terra, 1976.

Alfabetização de adultos: um quefazer neutro? Educação e Sociedade, São Paulo, n.1, p.64-70, set. 1978.

"Caminhos de Paulo Freire" [Entrevista]. Revista Ensaio, São Paulo, n.14, 1985c.

. Cartas à Guiné-Bissau. Rio de Janeiro: Paz e Terra, 1980b.

. Conscientização. São Paulo: Moraes, 1980a.

. Conscientização e alfabetização. Revista Estudos Universitários, Recife, n.4, 1963.

. Debate em João Pessoa no Mestrado em Educação/UFPB, 1986. [mimeografado]

Educação como prática da liberdade. 15a. ed. Rio de Janeiro: Paz e Terra, 1984a.

Educação e atualidade brasileira. Recife, 1959. [mimeografado]

Educação e mudança. Rio de Janeiro: Paz e Terra, 1979.

Educação na cidade. São Paulo: Cortez, 1991.

Extensão ou comunicação? 7a. ed. Rio de Janeiro: Paz e Terra, 1983.

Paulo Freire ao vivo [Entrevista]. São Paulo: Loyola, 1983b.

Pedagogia da esperança. São Paulo: Cortez, 1992. 
Pedagogia do oprimido. 13a. ed. Rio de Janeiro: Paz e Terra, 1984b.

Política e educação. São Paulo: Cortez, 1993.

; BETTO, Frei. Essa escola chamada vida. São Paulo: Ática, 1986b.

; CECCON, Claudius et al. Vivendo e aprendendo. São Paulo: Brasiliense, 1980.

; FAÚNDEZ, Antonio. Por uma pedagogia da pergunta. Rio de Janeiro: Paz e Terra, 1985b.

; GADOTTI, Moacir; GUIMARÃES, Sérgio. Pedagogia: diálogo e conflito. São Paulo: Cortez, 1985a.

; GUIMARÃES, Sérgio. Aprendendo com a própria história. Rio de Janeiro: Paz e Terra, 1987b.

; GUIMARÃES, Sérgio. Sobre educação. Rio de Janeiro: Paz e Terra, 1982b, v.1.

; GUIMARÃES, Sérgio. Sobre educação. Rio de Janeiro: Paz e Terra, 1984d, v.2.

; NOGUEIRA, Adriano. Na escola que fazemos. Rio de Janeiro: Vozes, 1988.

; SAVIANI, Dermeval et al. Documento interno (sobre educação) do Partido dos Trabalhadores (PT). São Paulo.

[mimeografado]

; SHOR, Ira. Medo e ousadia: o cotidiano do professor. Rio de Janeiro: Paz e Terra, 1987a.

PAIVA, Vanilda. Paulo Freire e o nacionalismo-desenvolvimentista. Rio de Janeiro: Civilização Brasileira, 1980.

ROSSI, Wagner. Pedagogia do trabalho: caminhos da educação socialista. São Paulo: Moraes, 1982.

SCOCUGLIA, Afonso C. A história das idéias de Paulo Freire e a atual crise de paradigmas. 2.ed. João Pessoa: Editora Universitária - UFPB, 1999. 182p.

TORRES, Carlos. Diálogo com Paulo Freire. São Paulo: Loyola, 1979.

WEFFORT, Francisco. "Educação e política" [Prefácio]. In: FREIRE, Paulo. Educação como prática da liberdade. Rio de Janeiro: Paz e Terra, 1984.

Recebido em 10 dez. 1999

Aprovado em 16 ago. 2000

Afonso Celso Scocuglia é professor da área de História e Filosofia da Educação do Departamento de Fundamentação da Educação - Centro de Educação - Universidade Federal da Paraíba. É atualmente vice-coordenador do Programa de Pós-Graduação em Educação da UFPB. Publicou várias obras sobre Paulo Freire e educação popular. 